\title{
Critical Success Factor of Trusted Elements for Mobile Health Records Management: A Review of Conceptual Models
}

\author{
Fatin Nur Zulkipli ${ }^{1}$ \\ Nurussobah Hussin ${ }^{2}$ \\ Faculty of Information Management \\ Universiti Teknologi MARA \\ Puncak Perdana, Selangor, Malaysia
}

\author{
Saiful Farik Mat Yatin ${ }^{3}$ \\ Institute for Big Data Analytics and \\ Artificial Intelligence \\ Universiti Teknologi MARA \\ Selangor, Malaysia
}

\author{
Azman Ismail $^{4}$ \\ Universiti Kuala Lumpur Malaysian \\ Institute of Marine Engineering \\ Technology, Lumut, Perak \\ Malaysia
}

\begin{abstract}
Health Information Technology such as Mobile Health Record Management (MHRM) and Electronic Health Record (EHR) depend on each other in maintaining the patients' medical record. For maintaining trust specifically in health information technology development, the relationship among the patients, providers and clinicians needs to be maintained. The present study consists of the understanding of the importance of the trusted elements of mobile health (mHealth) record management implementation in government hospitals. Covid-19 pandemic situation force obeying the technological approach in healthcare delivery. Technology gives a big impact on healthcare industry that deals with confidential data and human life. The increased use of mobile in records management in the wrong way leads the practitioner and communities towards poor quality, security problems, and meaningless data. To fulfil this objective, the conceptual framework has been developed by producing the trust elements for the implementation of mHealth apps in hospitals. Secondary data have been used and analyses to justify the objectives of the study. The findings and discussion have been evolved on correlating the existing literature and the analyses data. Five trusted elements for MHRM have been found: Governance, Professional skills and competency, Mobile Health Records Management (MHRM), Sustainability and, Technological. This paper has evolved the use of electronic health records in the health organizations for the accessibility of trust data and timely access. The involvement success factors of trust elements avoid the petty problem, and inefficient process but giving users convenient and instant access to patients' records.
\end{abstract}

Keywords-Electronic health record; mobile health record; records management; health information technology; records trust

\section{INTRODUCTION}

The advancement in the medical sciences has changed the customers' awareness and transformed the organizations by providing health services in the competitive environment [1]. Sometimes the critical need of the health system cannot be achieved due to the lack of proper documentation of the required papers between the health providers, data processing and timely access [2]. Hence, the need of access to computerbased information has been considered important. The EHR have been executed by hospitals at a rapid scale in recent years across the world [3] and defined as the digitalized format constituting a patient's health-related information that is stored

Institute for Big Data Analytics and Artificial Intelligence (IBDAAI), Universiti Teknologi MARA (UiTM) and Universiti Teknologi MARA Geran Insentif Penyeliaan (600-RMC/GIP 5/3 (018/2021). in the computer [4]. This EHR helps to provide easier access of health information such as patient's medical history, their medication, diagnosis, radiology images, lab results and other related medical information to the authorized providers among practitioners. The government has also taken major initiatives concerning the regulation and financial stimulations in different countries such as the USA, UK and Denmark [5] and [6]. The implementation of EHR in hospitals involves the integration and availability of data of the patients by improving the cost-efficiency and establishing good relationships among the patients and doctors. Health care professionals is the primary function in maintaining the nature of the hospital for efficient service [7]. The implementation of EHR helps in providing quality care along with customer satisfaction, cost effectiveness and timely access for complete and precise information [8] and [9]. Although the studies have provided several advantages of EHR, its implementation in the healthcare organizations have been found to be quite complex as its success and productivity depends on various factors [10] and [11]. Dissatisfactions among the patients have caused new exchanges that fulfil their needs by offering them several medical services online. This can be resolved by adopting the mHealth that consists of important information on the patient's medical history. The use of mHealth services has become efficient towards providing medical care. mHealth has been mostly used for disease investigation, treatment assistance, epidemic outbreak tracking and chronic disease management.

The access to mHealth has been considered complex due to the need of infrastructure investment and implementation of several changes in the health system. It also requires the user adaptability for participation in the development of the system [12] and [13]. The success in the implementation of EHR is mainly contributed by factors related to organizational, technological, and human [12]. The human factors include establishing the teamwork for users' participation along with selection of leadership, users gaining training for using the system and providing appropriate support for the promotion and maintenance of the system. Factors related to organization includes the involvement of clinical, administrative and information technology in the healthcare system. The training of knowledge and skills for working with EHR have been provided to the users along with the assurance of the 
confidentiality and security of the data in the healthcare organization. The technological factors involve the usability, infrastructure, interoperability, adaptability, testing and regulation, standards, and policies of the healthcare system.

Almost seven billion individuals are connected to this mobile network, and around 500 million people use personal mHealth apps around the world [14] and [15]. Hence, Hospitals and clinics can use this visibility and usefulness to reach out to patients in the most efficient way possible. The mHealth applications which helps in appropriate management, organization, documents' tracking and maintaining the record for further medical practice has been found to be efficient [16]. Also, the mHealth services maintains the mobile files while managing the workflow using electronic healthcare record management. Mobile files are effective in managing and organizing the paper or system information of the patient's data that helps in treatment procedure by further analysing the history. Trustworthiness of mHealth apps involves the trusted relationship established between the user and the mHealth app to benefit their health which is dependent on mobile health record data. Trustworthiness involves the attributes that are necessary for the individuals [17] such as honesty, competence, and reliability. These are some important trustworthy signals that must be maintained among the users while using the mHealth apps. Therefore, several healthcare models have been developed to cater the need of the increasing healthcare services. Trust elements for mHealth has been one of such models which has been considered as an important model in terms of effective accessibility, affordability, and usability. The use of mHealth in the hospitals have been capable of establishing good communication between the providers and the patients and help in improving the management system of the workflow in hospitals. The mHealth apps have been capable of providing effective communication streamlined between the patients, providers and caregivers allowing 24/7 services as per the condition of the patients.

\section{LITERATURE REVIEW}

\section{A. Concept of Electronic Medical Records and Mobile Health Records}

An EHR document has been considered as an official health document of any individual that is shared among multiple agencies and facilities. It is the digital version of the patient's information, and many consumers are adopting the desire for mobile access to their health records. EHRs are realtime records that available at an instant with security to the authorized users [18]. Health records consist of the medical and treatment history of the patients while an EHR system is the process of going ahead of standardized data collected data in the healthcare organization and is considered to be inclusive with a broader view of patient's care. Therefore, an EHR basically consists of a patient's medical history, diagnosis, treatment strategies, medications, dates for immunization, allergies, images of radiology and laboratory tests [20]. Among all other types of data EHR also involves contact information, information concerning the visit of the patient to healthcare professionals, insurance information, family history, information regarding the patient's condition if suffering from any disease, records of hospitalization and information regarding the surgeries. It also maintains an automated and streamlines provider workflow. One of the important and distinct characteristics of EHR is that all the information related to the health condition of the patient is present in the digitized format with the providers and the authorized providers are capable of managing this document by collaborating with other healthcare providers from multiple organizations [19]. Hence, it can be said that using EHR in the organization helps in building a healthier future for the nation.

The mHealth record has been efficient in improving the quality concerning patient's care and other related care provision [16]. The applications were created utilizing mHealth records, which aims to improve the accessibility and availability of medical records information to make it easier for hospitals and doctors to analyze patients' daily medical activities. The use of android and iOS platforms have contributed to the initiation of the mobile EHR application. The app's mHealth record involves inpatient, outpatient, and emergency patient information; operation schedule; verbal orders; medical consultation; searching patients; on-duty scheduling views; salary views; cafeteria menu; telephone directory; and groupware board [20]. Also, it has been analyzed that the development and adoption of mobile as a new platform in hospitals requires the cooperation of hospital executives.

The program regulations for EHRs and MHRs such as Medicare and Medicaid have been evolved to meet certain criteria. These regulatory programs help EHRs and MHRs to meet specific standards and criteria to ensure the data are trustworthy [21]. The healthcare professionals from the hospitals and healthcare system are assured by using these regulatory programs that EHR and MHR consist of the technologies with technical capabilities, functions, and security for catering the important requirements. However, digitalization has disrupted the healthcare sectors in many ways. Previously, the documented files were used in the form of papers for storage, management and retrieval of data containing patient's information as clinical perspectives. The transformation of a documented-based storage system into EHR has been proved to be efficient in the healthcare system. But this transformation has evolved various issues which have been faced by the providers that need proper resolution. Some major potential issues have evolved that consist of security issues, reduction in data flow, requirement for extra staff training and aspects of slowing down of the system while implementation of the data record of the patient. The findings were categorized under one general themes in Table I, Issues and Challenges of Trusted Mobile Health Records Management in Healthcare. Findings from the review are summarized in Table I and details framework of trust element MHRM are discussed in-depth in the following sections.

Thus, according to [29] and [30], health information management in the healthcare industry is highly critical to develop a comprehensive process for health records management. Consequently, one of the strategies areas on Malaysia Planning - 11 (RMK-11) is to achieve a trusted foundation, integration, and interoperability on mobile application, system transformation, and future-readiness preparation. To achieve the strategies, various elements are 
significant to be accounted in planning health records management to ensure data are trustworthy and accurate over the complete records lifecycle. Thus, this article concerns to provide trusted elements in handling patient data to avoid any difficulties and risks on mobile health records towards critical success for MHRM implementation. The analyses also provide a records management framework for readers to understand the sources of the elements.

TABLE I. Issues and Challenges of Trusted Mobile HeAlth Records Management in HealthCARE

\begin{tabular}{|c|c|c|c|}
\hline Theme & $\begin{array}{l}\text { Types of Issues } \\
\text { and Challenges }\end{array}$ & Explanation & Author(s) \\
\hline \multirow{4}{*}{$\begin{array}{l}\text { Issues and } \\
\text { Challenges of } \\
\text { Trusted Mobile } \\
\text { Health Records } \\
\text { Management in } \\
\text { Healthcare }\end{array}$} & Security & $\begin{array}{l}\text { The security of the data has been the major concern. The electronic records of the } \\
\text { patient's information can be hacked from the data storage system if the software } \\
\text { containing those data is not updated timely and secured [22]. Therefore, a security audit } \\
\text { of the healthcare organization is needed for maintaining the security of the patient's } \\
\text { record. The electronic health records are designed for streamlining the workflow of the } \\
\text { healthcare organization. Hence, these streamlines are created by the developers who are } \\
\text { sometimes responsible for creating clunky and difficult work. Also, the staff working } \\
\text { with these complex streamlined workflows may require more time for entering the basic } \\
\text { information or retrieval of the appropriate record in the system. The transformation of } \\
\text { the paper-based information of the patients into a new electronic healthcare record } \\
\text { system requires implementation of some additional work. Hence, appropriat instructions } \\
\text { need to be given to the staff for handling EHR effectively. Therefore, insufficient } \\
\text { knowledge and skills related to the handling of EHR may disrupt the proper functioning } \\
\text { of MHRM in the healthcare system due to less efficacy in the workflow. }\end{array}$ & {$[22]$} \\
\hline & Data privacy & $\begin{array}{l}\text { Another major issue involves the data privacy of the patients. The stakeholders are often } \\
\text { concerned with the patients' data privacy of getting leaked due to the increase of } \\
\text { cybercrime. Lack of appropriate planning and communication proved to be the issues } \\
\text { that resulted in the failure of meeting the expectations of the customers adopting } \\
\text { MHRM. }\end{array}$ & {$[23],[24],[25],[26]$} \\
\hline & $\begin{array}{l}\text { Lack of } \\
\text { technological } \\
\text { knowledge }\end{array}$ & $\begin{array}{l}\text { Another major issue involves the lack of technological knowledge among the medical } \\
\text { staff members for implementation of EHR [10] and [11]. Also, have several health } \\
\text { workers have doubts concerning the value of the EHRs. They may show unwillingness } \\
\text { to give up the documentation process. The staff are not aware of the technological } \\
\text { advancement which results in delay in EHR implementation. The medical doctor finds it } \\
\text { hard to fit with the workflow of the EHR. The software's usability is hampered by } \\
\text { design defects or inadequate training. }\end{array}$ & [10] and [11] \\
\hline & $\begin{array}{l}\text { Technology } \\
\text { advancement }\end{array}$ & $\begin{array}{l}\text { The mHealth apps have been evident and it has been confirmed that almost } 97,000 \\
\text { mHealth apps have already been used across } 62 \text { app stores [27]. One of the reports has } \\
\text { revealed that the global mHealth market was predicted to increase from } \$ 6.21 \text { billion } \\
\text { revenue in } 2013 \text { to } \$ 23.49 \text { billion by the year } 2018 \text { [28]. The potential use of mHealth } \\
\text { services in Malaysia has been considered as an alternative delivery channel. This } \\
\text { increasing growth of mHealth has led towards the drastic change in the management of } \\
\text { the health data with the paradigm shift from mainframe systems situated in the facilities } \\
\text { of the healthcare providers towards the apps and other storage systems. It has evolved } \\
\text { into a new openness. Previously, the devices were available only in the hospitals, but the } \\
\text { development of mHealth apps has evolved flexibility by providing the clinicians with all } \\
\text { types of useful resources for the treatment even if located remotely. Hence, this trending } \\
\text { use of mHealth services has facing trust data concerns while maintaining the } \\
\text { accessibility and cost-efficiency. The population of this new era is now completely } \\
\text { dependent on the digitalized technologies and hence require ease for receiving care. }\end{array}$ & [27] and [28] \\
\hline
\end{tabular}

\section{CONCEPTUAL FRAMEWORK}

A healthcare organization initiates mHealth services that majorly involves the clinicians and patients. The major trust elements involved while using mHealth apps by the clinicians includes the adoption of technology, time, awareness, and familiarity with the services. The data of the patients are presented and recorded in EMR and hence the maintenance of privacy and security is the major concern to provide trusted data while implementing mHealth services. Exploring various ideas, frameworks, concepts, and models from connected subject matter is important in selecting the best practise towards the goals of MHRM. The conceptual framework for the given study has been described below:
A. A Trusted Electronic Records Management Framework

Figure 1 explains the credibility and authenticity of electronic records that helps in determining the legacy of the electronic documents along with their effectiveness, preservation value and reproduction history. The activities of electronic record management are ensured by determining the evidence retention and utilization of information. An employment framework of electronic records trusted management based on critical business process management has been constructed by [31]. Yet, this framework is focusing on Government-Controlled Companies not in a healthcare environment as focusing on this study. In consideration of the foregoing, the principles of electronic records in any organization including healthcare, it is depending on the related trusted elements. Hence, the author believes, this model one of the models to consider off. 


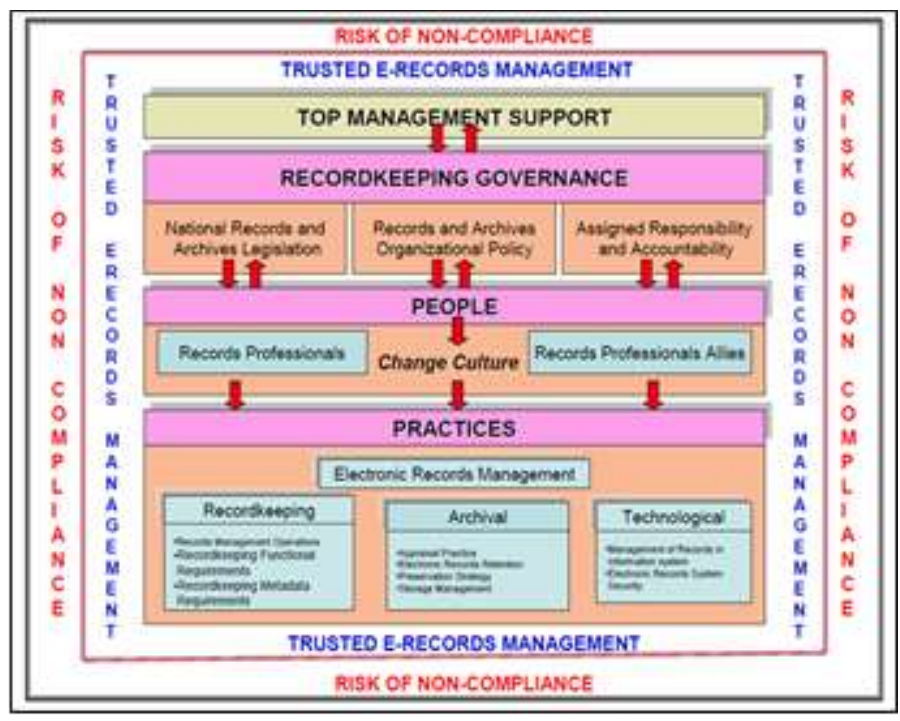

Fig. 1. A Trusted Electronic Records Management Framework [31].

\section{B. MITHRIL Conceptual Model}

Security and privacy are perhaps the most pressing concerns when it comes to the use of mobile platforms in organization. Privacy refers to who has the authority to govern our personal data, whereas security refers to how that authority protects our data. There must have been concerns about security and privacy when mobile devices were first introduced to society. When mobile devices have been introduced to society, there must have been concern about the security and privacy of mobile platforms. [32] in figure 2 highlights, MITHRIL framework is used as a mobile access control framework that permits us to capture access control needs for specific users. This model has described the prevention criteria from the damage of personal data or information. MITHRIL framework which has two major components i.e MithrilAC and Heimdall also contains application analytic system that gathers mobile application metadata.

MithrilAC in figure 2 is the main component of MITHRIL that manage access control on the device. The access and security classification which conduct for security reason and confidential only allows authorized person to access the data in the devices. The second component, Heimdall, detects and prevents infections on mobile devices, tablets, and computers. Using crowd-sourced policy rules such as malware threat for our devices, Heimdall intends to classify applications and generate an initial set of policy rules. Those threats will be sensed and blocked before it can manipulate our personal data. Thus, Heimdall work as a tool that classify the threats which may affect our devices especially the personal data or information.

\section{Conceptual Model for Clinician Mobile Health Readiness}

MHealth in figure 3 is the practice of providing medical treatment and public well-being through mobile devices. It benefits both the health care practitioner and the patient by increasing productivity and efficiency during the pharmaceutical procedure. The barriers of physicians and related healthcare organizations are assessed for the adoption of mHealth along with the use of EHR data of the patients.

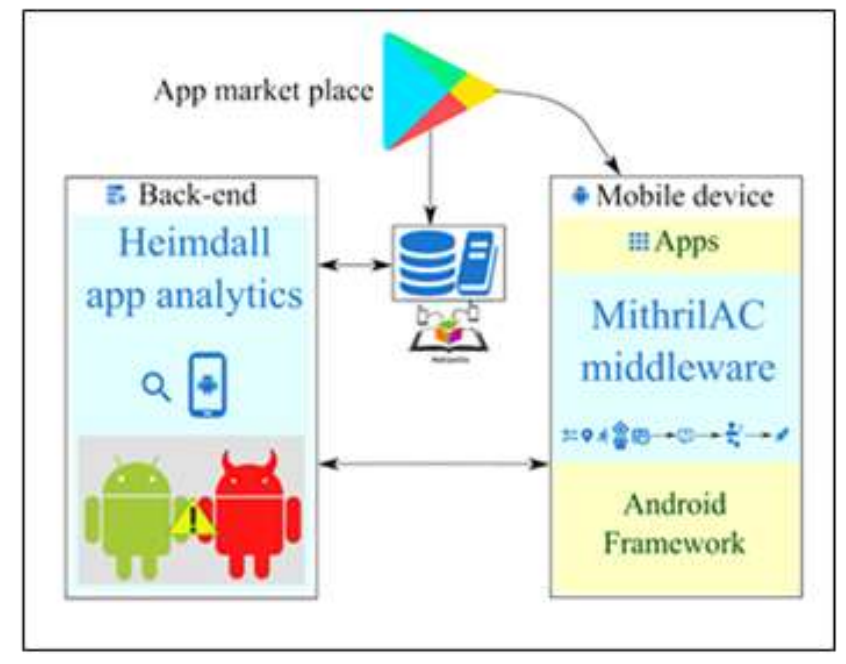

Fig. 2. MITHRIL Conceptual Model [32].

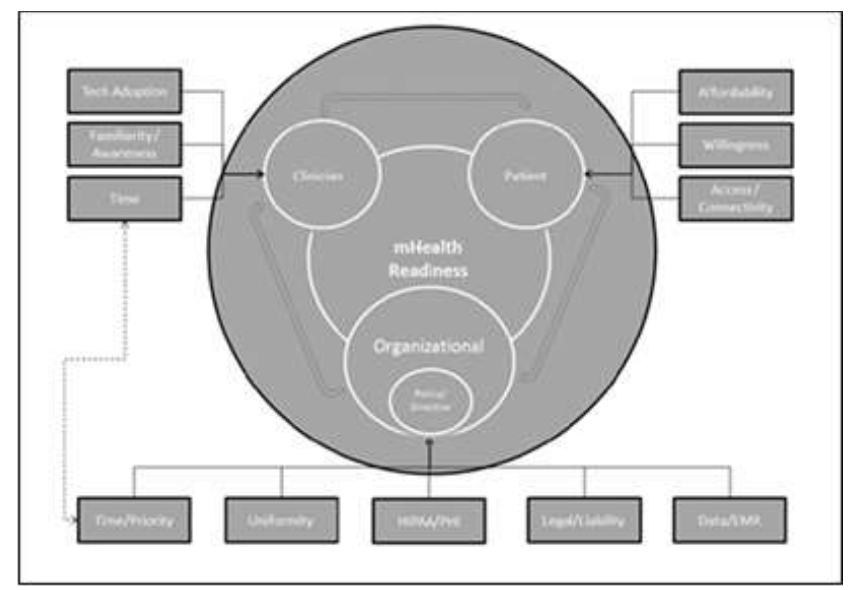

Fig. 3. Conceptual Model for Clinician mHealth Readiness [33].

Figure 3 shows, doctors, nurses, and pharmacists rely on mobile health to keep track of their patients. This technological implementation allows them to have consultations with their patients and to save all their patient information in digital form, making it easier for them to track down all the information they require. Simultaneously, this will reduce time in searching and retrieving the data in the mobile device. When their hospital number or identity card number is keyed into the system, all patients who register in the hospital will automatically appear in the system. In addition, mHealth create alertness to the health care professional and patients in dealing with medical treatment. Patients can just check at their smart phones to see what they need to do to improve their quality of health. When the doctors are not there, it serves as a personal advisor for the patients.

\section{Conceptual Operating Model for MMAs}

Figure 4 is model for Mobile Medical Apps (MMAs) has involved new ways for innovation with low cost healthcare delivery. This model involves the estimation of the MMA interactions with human physiology. Therefore, it is essential to have evidence of their trustworthiness i.e. maintaining privacy of health data, long term operation of wearable sensors and ensuring no harm to the user before actual marketing. 


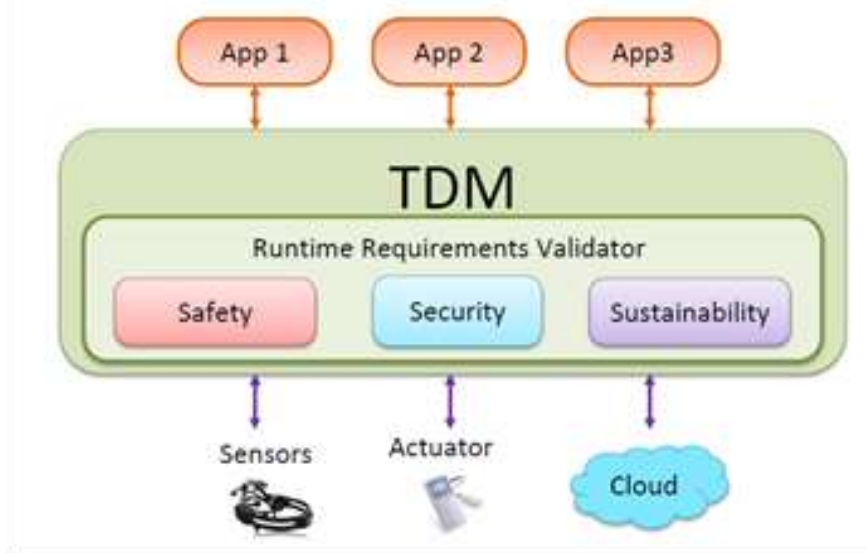

Fig. 4. Conceptual Operating Model for MMAs [34].

\section{E. OAIS Functional Entities Model}

The Open Archive Information Systems (OAIS) is a type of archival system that employs both human and technological resources. According to [35] in figure 5, there are six functional entities in an Open Archival Information System, as mentioned by the Consultative Committee for OAIS. OAIS model can provide conceptual framework concerning the preservation and dissemination of digital assets. It defines a set of roles, processes, and functions relevant to long-term preservation. Thus, the OAIS model provides us with a common understanding of what the archives do when they preserve digital information objects. Furthermore, it has laid the groundwork for greater standardisation in the field of digital preservation, including the development of criteria and procedures for analysing and evaluating archival preservation and distribution practises.

Figure 5 reveals the first functional entity is receiving information from producers and packages it for storage. The producer will do the Submission Information Package (SIP), then creates an Archival Information Package (AIP) from the Submission Information Package (SIP) and transfers the newly created Archival Information Package (AIP) to archival storage. Second functional entity is the archival storage function that serves as a repository to stores, maintains, and retrieves archival information. The third functional entity is the data management function that works to coordinates the descriptive information of the archival information package and the system information that supports the archive. The fourth functional entity is the preservation planning to support the archives material which make it accessible to the consumer. The fifth functional entity is the administration function to manage the daily operations of the archives. It handles the users need of the system. It works from the registration, searching, retrieving, and circulating of the archival material. The last functional entity is the access function through registering to the person in charge. This is to make sure the improvement of the security operation increasing to the maximum to keep the archival material stay on its place well.

Preliminary high-level evaluation of aspects of trustworthy recordkeeping addressed in blockchain recordkeeping solutions based on a generic reference architecture and operating model.

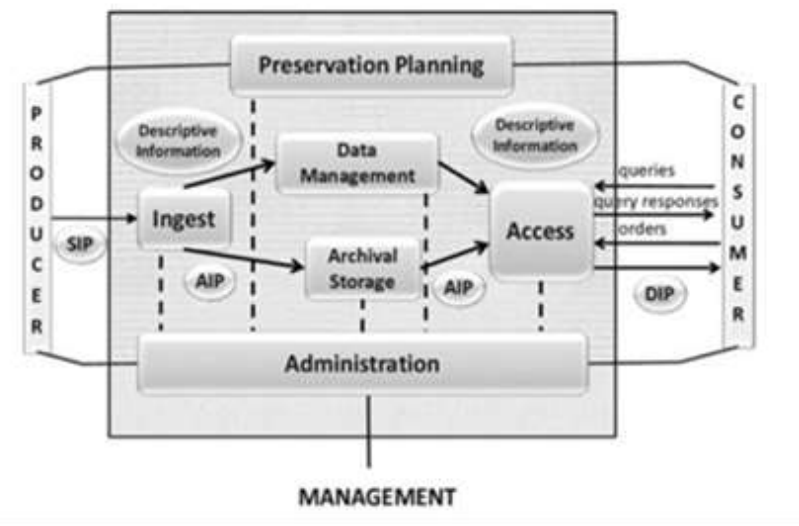

Fig. 5. OAIS Functional Entities Model [35].

Blockchain is a database that is controlled by a computer and is not owned by a single person. According to [36], blockchain is an open-source technology that allows for reliable, immutable records of transactions to be stored in decentralised, distributed, and automated ledgers that are publicly accessible. The government and the public sector are beginning to recognise the significance of this technological breakthrough. The blockchain system can help make transaction processes more efficient.

Figure 6 shows the trusted documents, according to [36], must be accurate, reliable, and legitimate. To have the feature of evidence, these three traits must remain unified. Simply said, accuracy means that all the data in the records is correct for the operation.

As a result, to clarify the significance of numerous concepts from diverse matters, the researcher separated the subject matter or theme into five associated subject matter or themes that address problems. This study reviewed five theories and conceptual models as state in figure 1,2,3,4,5, and 6 related to five elements: Governance, Professional Skills and Competency, Mobile Health Records Management (MHRM), Sustainability, and Technological.

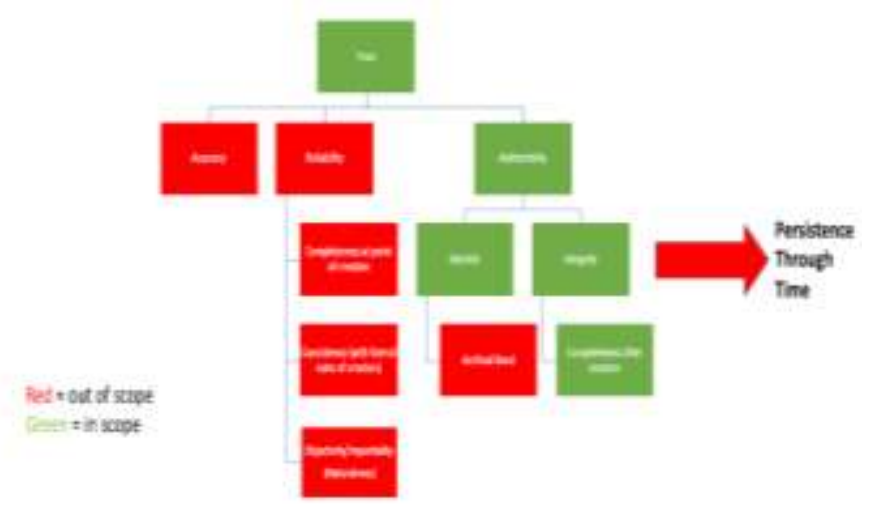

Fig. 6. OAIS Functional Entities Model [36].

These six models detail out the elements of best practices required to effectively manage the mobile electronic health records. As a result, [37] agrees that the lack of a proper standards aspect for mobile health record-keeping in mobile 
systems is the primary reason why this topic continues to be debated. According to [3], to tackle this problem, the mobile device system needs precise policies, standardised elements for medical records coordination, and adaptive technology. It details out the elements of best practices required to effectively manage the mobile electronic health records. These attributes are encapsulated in the trusted environment whereby any short fall will implicate the organization and will lead to the risk of non-compliance. In other words, health records management should be recognized as a generic framework to the organization's information strategy, especially in meeting the statutory legal and audit demands to ensure the trustworthiness of the records. Table II shows a list of frameworks/models/concepts/theories for use in this study that are linked to the MHRM's trusted elements.

TABLE II. THE UNDERPINNING MODELS TOWARDS TRUSTED ELEMENTS OF MHRM

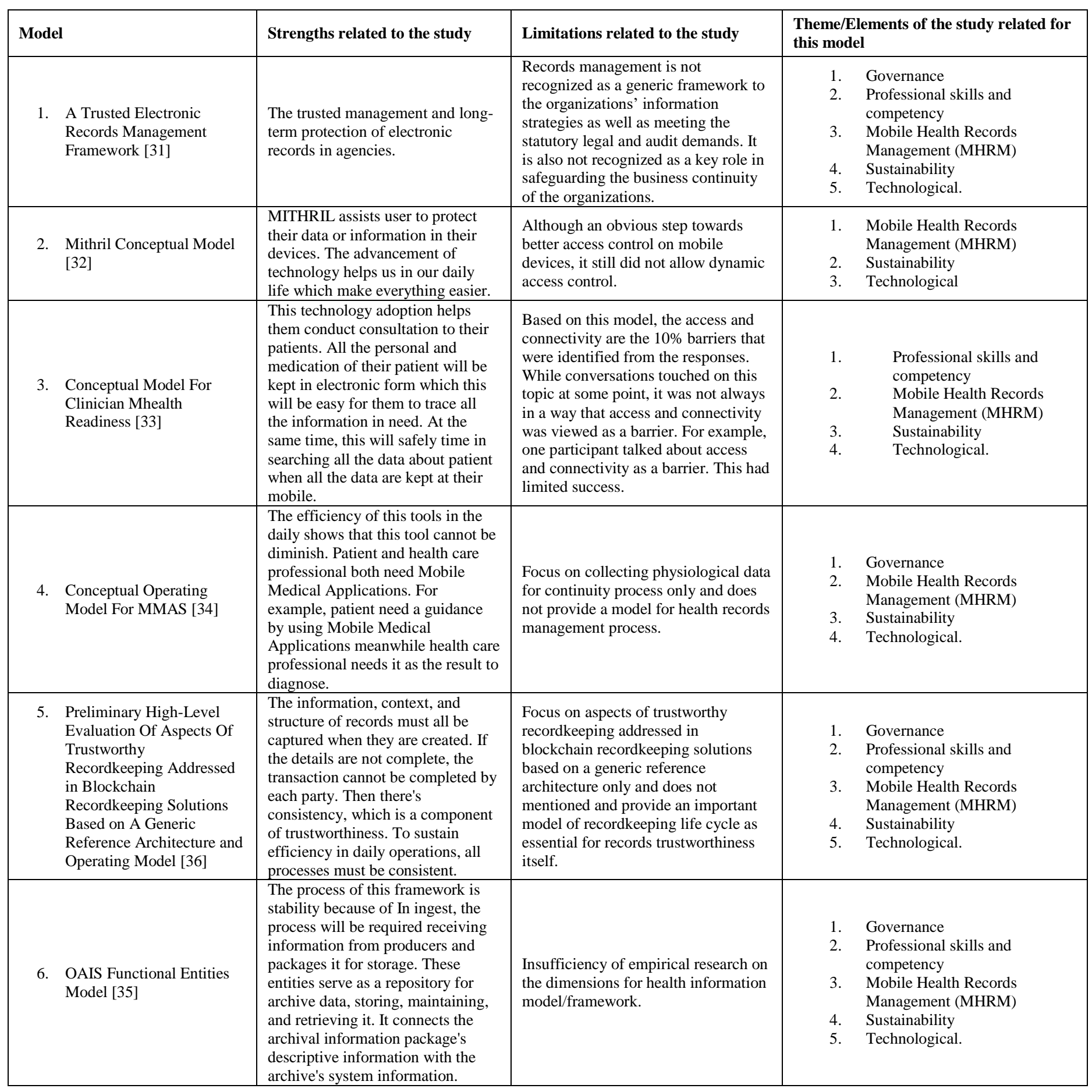


Thus, this research solely focuses on the needs of trusted elements for the success factor of trusted elements for MHRM adoption of MHRM in healthcare organization. As described by other authors in the literature, the elements are crucial to ensure healthcare organization have a comprehensive rule and regulation of mobile device in term of standard, elements for records coordination, adoptive technologies, policies, and security [35]. Hence, the results are interesting and help to show the important theme/element for the trusted elements of MHRM are Governance, Professional skills and competency, Mobile Health Records Management (MHRM), Sustainability, and Technological. These themes/elements are based on other researchers' findings as a guide to advance the electronic records specifically in adoption into mobile for health records management in Malaysian.

\section{SIGNIFICANCE OF THE STUDY}

The electronic health records and the mHealth records have been found to be effective in maintaining the personal health records of the patients in digitized format ensuring the safety and confidentiality of the data. These electronic health records are now present in the mobile format. mHealth records have enabled the patients to access their health information through internet and telecommunication devices. Hence, it has evolved the initiation of mHealth services for the ease of the patients and clinicians. The mHealth apps have the potential to help the patients and providers in identifying the medical conditions prescriptions accordingly from the different locations that helps in reducing the medical errors and enhances the improvement in health conditions during the emergency condition at the time of treatment with the new providers. The ease of access to the data of patients have been another major important characteristic of the mHealth services. The satisfying result from patients and management based on previous experiences of the implementation as discussed above demanding from the practitioners for enhancement of workflow process by using MHRM since the mobile device is beneficial in the collection, assessment, amendments, and transfer of data proficiently. Now, the medical conditions of the patients are recorded and submitted in digitized format that has helped the clinicians to treat their patients from remote locations. As a result, any adoption of technology for health records management in hospitals complied with the right principle such as trusted elements as suggest by author lead to trust, confidence, and secure feelings for users who involved in the health records process from the creation until disposal. This will be resulted in well-organized records, reduce file storage space, difficulties for updating reports at the workstation, and prevent manual handling of files that delay time for patients and wasted money in recruiting staff. This was because the usage of mobile will be easier, faster, and efficient. The petty problem such as distance workstations, delay time for data updating or inefficient process can be avoided through mobile device management, but also gives users convenient and instant access to patients' records. Besides, the cost efficiency is also maintained as the daily visit to the hospitals have been reduced due to access through mHealth apps in the mobile devices.

\section{LIMITATIONS}

The present study has also involved certain limitations include the unawareness of use of EHR among the patients and medical professionals that results in providing lack of important information while maintaining the patients' record. These issues give a big impact on accuracy, consistency, and integrity of the data. Another major limitation involves the cost as many of the healthcare system cannot bear the high cost software for maintaining the data security and confidentiality of the patients. This may result in the loss of important data from the electronic system.

\section{CONCLUSION}

The implementation of trusted elements of MHRM has led to a positive impact on the health conditions of individuals. The existing knowledge and understanding about the trusted elements of EHR has helped in understanding the basic aspects of MHRM and its effect while adopting it in the government hospitals for enhancing the technology adoption. The literature review of the given study has provided evidence that has implicated the elimination of the traditional approaches in the healthcare system and adopted the technology perspectives for providing care to the patients with accurate health information. The important trusted elements have played a major role in maintaining the ethical consideration of using the mHealth record management in hospitals. These trusted elements in turn affect the healthcare environment and hence, the results implicated the positive impact of using mHealth services. Trust elements as mentioned all play a role in increasing the efficacy of a health organisation while maintaining a trustworthy data and smooth workflow.

\section{ACKNOWLEDGMENT}

This article is financially supported by Institute for Big Data Analytics and Artificial Intelligence (IBDAAI), Universiti Teknologi MARA (UiTM) and Universiti Teknologi MARA Geran Insentif Penyeliaan (600-RMC/GIP 5/3 (018/2021).

\section{REFERENCES}

[1] Zaid, A.A., Arqawi, S.M., Mwais, R.M.A., Al Shobaki, M.J. and AbuNaser, S.S., "The Impact of Total Quality Management and Perceived Service Quality on Patient Satisfaction and Behavior Intention in Palestinian Healthcare Organizations." Technology Reports of Kansai University., vol. 62, no. 3, pp. 221-232, 2020.

[2] Chuah, F.L.H., Tan, S.T., Yeo, J. and Legido-Quigley, H., "Health system responses to the health needs of refugees and asylum-seekers in Malaysia: a qualitative study." International journal of environmental research and public health, vol. 16, no. 9, p.1584, 2019.

[3] Kim, E., Rubinstein, S.M., Nead, K.T., Wojcieszynski, A.P., Gabriel, P.E. and Warner, J.L., "The evolving use of electronic health records (EHR) for research." In Seminars in radiation oncology, vol. 29, No. 4, pp. 354-361, 2019.

[4] Cowie, M.R., Blomster, J.I., Curtis, L.H., Duclaux, S., Ford, I., Fritz, F., Goldman, S., Janmohamed, S., Kreuzer, J., Leenay, M. and Michel, A., "Electronic health records to facilitate clinical research." Clinical Research in Cardiology, vol. 106, no. 1, pp. 1-9, 2017.

[5] Terziev, V., "The good practices in the regulation of social development." International E-Journal of Advances in Social Sciences., vol. 5, no. 14, pp. 568-578, 2019. 
[6] Lee, C. and Ma, L., "The Role of Policy Labs in Policy Experiment and Knowledge Transfer: A Comparison across the UK, Denmark, and Singapore." Journal of Comparative Policy Analysis: Research and Practice, vol. 22, no. 4, pp. 281-297, 2020.

[7] Glover, G., 2019. Relationships Between Nursing Resources, Uncompensated Care, Hospital Profitability, and Quality of Care.

[8] Krousel-Wood, et al., "Implementing electronic health records (EHRs): health care provider perceptions before and after transition from a local basic EHR to a commercial comprehensive EHR." Journal of the American Medical Informatics Association, vol. 25, no. 6, pp. 618-626, 2018.

[9] Ommaya, A.K., Cipriano, P.F., Hoyt, D.B., Horvath, K.A., Tang, P., Paz, H.L., DeFrancesco, M.S., Hingle, S.T., Butler, S. and Sinsky, C.A., 2018. Care-centered clinical documentation in the digital environment: Solutions to alleviate burnout. NAM Perspectives.

[10] Eichler, H.G., Bloechl-Daum, B., Broich, K., Kyrle, P.A., Oderkirk, J., Rasi, G., Santos Ivo, R., Schuurman, A., Senderovitz, T., Slawomirski, L. and Wenzl, M., "Data rich, information poor: can we use electronic health records to create a learning healthcare system for pharmaceuticals?." Clinical Pharmacology \& Therapeutics, vol. 105, no. 4, pp. 912-922, 2019.

[11] Setia, P., Menon, N. and Srinivasan, S.S., "EHR application portfolio and hospital performance: Effects across hospitals with varying administrative scale and clinical complexity." Information \& Management, vol. 57, no. 8, p.103383, 2020.

[12] Y.H. Sidek and J.T. Martins, "Perceived critical success factors of electronic health record system implementation in a dental clinic context: an organisational management perspective." International journal of medical informatics, vol. 107, pp. 88-100, 2017.

[13] Greenhalgh, T., Wherton, J., Shaw, S., Papoutsi, C., Vijayaraghavan, S. and Stones, R., "Infrastructure revisited: an ethnographic case study of how health information infrastructure shapes and constrains technological innovation.” Journal of medical Internet research, vol. 21, no. 12, pp. 16093, 2019.

[14] PR Newswire. 2015. The mHealth (mobile healthcare) Ecosystem: 2015-2030 - Opportunities, Strategies and Forecasts. PR News Wire. Retrieved from http://www.prnewswire.com/news-releases/the-mhealthmobile-healthcare-ecosystem2015--2030--opportunities-cha.

[15] Choi, W., Park, M. A., Hong, E., Kim, S., Ahn, R., Hong, J., Yeo, S., "Development of mobile electronic health records application in a secondary general hospital in Korea," Healthcare Informatics Research, vol. 19, no. 4. pp. 307-313, 2013.

[16] M. Idzwan and M. Salleh, "Evaluating The Performance of Malaysian Health Care Providers With Partial Least Squares Path Modeling Electronic Health Records ( EHRs ) System," pp. 1-27, 2020.

[17] O’Neill O., "Trust trustworthiness and transparency." Retrieved from https://www.efc.be/human-rights-citizenship-democracy/ trusttrustworthiness-transparency/ (2015, accessed 10 March 2019).

[18] Asulyan, T., 2018. Barriers to the Adoption of Electronic Health Records by Physicians in Hospitals.

[19] Rajkomar, et al., "Scalable and accurate deep learning with electronic health records." NPJ Digital Medicine, vol. 1, no. 1, pp.1-10, 2018.

[20] Jayewardene, D., 2020. Mobile Smartphone Applications for Healthcare Practitioners (Doctoral dissertation, University of Leeds).
[21] Espirito Santo, M. D. F. N., 2017. Evaluation of health outcomes associated with medication in southern Portugal using a novel approach for medication review: ReMeD study (Doctoral dissertation).

[22] K. M. Kuo, C. F. Liu, and C. C. Ma, "An investigation of the effect of nurses' technology readiness on the acceptance of mobile electronic medical record systems," BMC Med. Inform. Decis. Mak., vol. 13, no. 1, pp. 1-14, 2013.

[23] Roehrs, A., da Costa, C. A., da Rosa Righi, R., da Silva, V. F., Goldim, J. R., and Schmidt, D. C., Analysing the performance of a blockchainbased personal health record implementation, Journal of Biomedical Informatics, $\quad$ Vol 92, 2019,103140. https://doi.org/10.1016/j.jbi.2019.103140.

[24] Helmers, R., Doebbeling, B.N., Kaufman, D., Grando, A., Poterack, K., Furniss, S., Burton, M. and Miksch, T., Mayo Clinic Registry of Operational Tasks (ROOT): A Paradigm Shift in Electronic Health Record Implementation Evaluation, Mayo Clinic Proceedings: Innovations, Quality \& Outcomes, Vol 3, No 3, 2019, pp.319-326. https://doi.org/10.1016/j.mayocpiqo.2019.06.004.

[25] Choi, E., Xiao, C., Stewart, W.F. and Sun, J., "Mime: Multilevel medical embedding of electronic health records for predictive healthcare," arXiv preprint arXiv:1810.09593, 2018.

[26] Mukamba, N., Beres, L. K., Mwamba, C., Law, J. W., Topp, S. M., Simbeza, S., et al. How might improved estimates of HIV programme outcomes influence practice? A formative study of evidence, dissemination and response, Health Research Policy and Systems, Vol 18, 2020, pp. 1-11. doi: http://dx.doi.org/10.1186/s12961-020-00640-7.

[27] Ronchi, A.M., "e-Health: Background, Today's Implementation and Future Trends." In e-Services, pp. 1-68, 2019. Springer, Cham.

[28] Waldman L, Reed P, Hrynick T. Accountability in Health Systems and the Potential of mHealth.

[29] K. M. Andrews, "Best Practices To Establish Successful Mobile Health Service In A Healthcare Setting" Pepperdine University, 2016.

[30] S. Kim, "A mobile device security implementation model for a national medical center complying with the HIPPA security rule," 2016.

[31] Aliza, I., 2010. Assessing the practice of trusted electronic records management in Malaysia government-controlled companies (Doctoral dissertation, Universiti Teknologi MARA). Retrieved from http://ir.uitm.edu.my/id/eprint/5106.

[32] P. K. Das, "Context-Dependent Privacy and Security Management on Mobile Devices," ProQuest Diss. Theses, p. 147, 2017.

[33] B. P. Weichelt, "Health in Your Hand: Assessment of Clinicians' Readiness To Adopt Mhealth Into Rural Patient Care," ProQuest Diss. Theses, pp. 1-104, 2016.

[34] Priyanka Bagade, "Evidence-based Development of Trustworthy Mobile Medical Apps," ProQuest Diss. Theses, pp. 1-144, 2015.

[35] V. L. Lemieux, "Trusting records: is Blockchain technology the answer?,” Rec. Manag. J., vol. 26, no. 2, pp. 110-139, 2016.

[36] V. L. Lemieux, "Blockchain And Distributed Ledgers As Trusted Recordkeeping Systems," November, pp. 41-48, 2017.

[37] A. Murad, "the Impact of Mobile Health Applications on Emergency Medical Services and Patient Information Privacy Phd Dissertation ( 3Paper Format ) By Claremont Graduate University - Center of Information All Rights Reserved .," Claremont Graduate University, 2014. 